\title{
Editorial
}

\section{Division of Acta Crystallographica}

Beginning with Volume 39 in January 1983, Acta Crystallographica will be published in three sections:

\section{Section A - Foundations of Crystallography; One Volume, six parts per year. \\ Section B - Structural Science; One Volume, six parts per year. \\ Section C - Crystal Structure Communications; One Volume, twelve parts per year.}

Acta was founded in 1948 as the central place for the publication and discussion of crystallographic research. P. P. Ewald stated in the Editorial Preface to the first issue that:

'It is ... felt that a considerable body of investigations on crystalline and kindred substances would find a more appropriate place in a journal [such as Acta] devoted to the detailed study of individual substances by the various methods, and to the further development of these methods [than scattered throughout the literature]. It is hoped that Acta will fulfil this useful function, ... that all important new lines of research will be represented in it, and that Acta will focus international discussion of problems of crystallography.'

Many of the original expectations for Acta had, in large measure, become satisfied by the mid-Sixties. The full range of current crystallographic research, nevertheless, was not well represented in the journal although Acta had grown from 344 pages in 1948 to 2076 in 1967. It was noted by the Executive Committee [Acta Cryst. (1967). 23, 870-871] that:

'Acta has proved to be particularly effective as the prestige journal for the publication of papers related to the theory, techniques, and results of crystalstructure analysis.'

A by-product of this success had been a decreasing percentage of papers submitted on the more physical aspects of crystallography. In consequence, the Executive Committee divided Acta in 1968 into Section A, devoted to crystal physics, diffraction, theoretical and general crystallography, and Section B, devoted to structural crystallography and crystal chemistry. At the same time, the Journal of Applied Crystallography was launched as a forum for papers concerned with methods, apparatus, problems and discoveries in applied crystallography.
The combination of automatic diffractometers, powerful and inexpensive computers, improved phase determining methods, and efficient computer programs has resulted in the solution and refinement of certain types of crystal structure becoming appreciably more straightforward since 1968. The consequent large number of reports of such structure determinations has had a marked tendency to deter the submission to Section B of papers on structural science in which the relationship of atomic arrangement to chemical, physical, biological, metallurgical, mineralogical and other important properties is considered. Many excellent papers on structural science, such as those presented at the Twelfth International Congress of Crystallography, have instead been directed to other journals in past years because there was no central journal specifically designed for them.

The new Section B of Acta now welcomes the submission of interesting structurally based papers from disciplines throughout the natural sciences. The purpose of this new section is to provide a showcase for exciting papers on all aspects of structural science, in which they can be published only in the company of similar papers.

Certain types of structurally oriented papers which in recent years have been allocated to Section A will now be seen clearly to belong to the new Section B. The new Section A has therefore been given the title Foundations of Crystallography. Papers concerned with basic developments in any area of crystallography should be submitted to Section $A$ in future.

The increasing flow of papers reporting crystal structure determinations led the X-ray crystallography group at the University of Parma to launch the journal Crystal Structure Communications in 1972. Edited by L. Cavalca and M. Nardelli and supported by the University of Parma, the journal has been very successful and published 1265 pages in 1980. The advent of Section $C$ will coincide with the absorption of Crystal Structure Communications and the continuation of its name as the new Section $C$ subtitle. The University of Parma has very generously agreed to transfer its copyright ownership to the International Union of Crystallography as a gift. The arduous editorial labor of the Parma group over the past ten years, and particularly that of L. Cavalca, M. Nardelli, A. Chiesi Villa, A. Gaetani Manfredotti, G. D. Andreetti, A. Bonamartini Corradi, C. Guastini, A. Mangia, A. M. Manotti Lanfredi, A. Musatti, G. 
Pelizzi, P. Sgarabotto, P. Domiano, V. Adovasio and A. Tiripicchio, is gratefully acknowledged.

The format of papers in Section C will resemble that presently used for Short Structural Papers in Section B of Acta but with important differences. Details of the new format will be given in the February 1982 issue of Acta B. Although there will no longer be a specific restriction on the length of papers, conciseness will remain an important criterion in their evaluation. All three sections of Acta will receive equally careful attention from editors and referees, with closely comparable standards applied to all papers. It is expected that Acta will continue to set the standards by which other journals judge crystallographic papers.

All papers submitted to Acta from 1 May 1982 should be written with the forthcoming division into three sections borne in mind. Details of the pricing policy for the journal will be published later in 1982 .

The Journal of Applied Crystallography will continue to be published with unaltered terms of reference, and with continued close cooperation between the Editors. 